\title{
Decompressive craniectomy for malignant middle cerebral artery infarctions: a meta- analysis
}

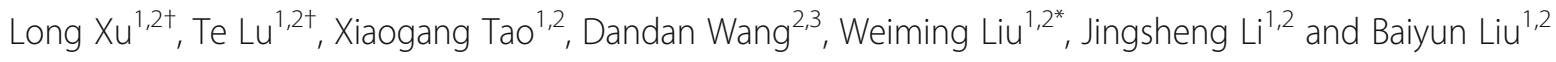

\begin{abstract}
Background: Decompressive craniectomy (DC) has been the classical management for malignant middle cerebral artery infarctions (mMCAl) in clinical practice. However, the association between DC and mMCAl remains unclear. This review went to evaluate the efficacy of DC in treating mMCAl patients.

Methods: Studies were entirely searched since the foundation dates of multiple databases to June 2016. All major databases were involved, including Cochrane Central Register of Controlled Trials, EMBASE, MEDLINE, and other sources. the bias risk of studies involved were evaluated. Modified Rankin Scale was defined as Primary outcome, Odds Ratio and 95\% confidence intervals was taken as measurements. T2 (tau-squared) test, 12 test, and chi-square tests were used for statistical heterogeneity evaluation for each meta-analysis result, followed by fixed-effect model. Mantel-haenszel method was used in the process of summary estimations. All of the meta-analysis was conducted by Review Manager 5.3.
\end{abstract}

Results \& Conclusion: One thousand one hundred forty-five records of data were critically identified and collected through databases and 14 studies were finally involved. Result suggested that DC can ameliorate the suboptimal outcome of mMCAl patients.

Keywords: Decompressive craniectomy, Malignant middle cerebral artery infarction, Meta-analysis

\section{Background}

Decompressive craniectomy (DC) has been the classical management for traumatic brain swelling since the time of Hippocrates [1]. Cushing was the forerunner who managed intracranial hypertension with modern surgical techniques [2]. Nowadays DC has been widely used in variety of cerebral diseases accompanied with critical high intracranial pressure state, such as traumatic brain injury, malignant middle cerebral artery infarctions (mMCAI) and intracerebral hematoma [3]. DC could release extra subcutaneous space for swelling brain tissue and make intracranial pressure decreased.

\footnotetext{
*Correspondence: Iwmttyy@163.com

${ }^{\dagger}$ Equal contributors

${ }^{1}$ Department of Neurosurgery, Beijing Tiantan Hospital, Capital Medical University, 6 Tiantan Xili, Dongcheng District, Beijing 100050, People's Republic of China

${ }^{2}$ China National Clinical Research Center for Neurological Diseases (NCRC-ND), Beijing 100050, China

Full list of author information is available at the end of the article
}

The pathological mechanism of mMCAI is explained as the chain effect of middle cerebral arterial(MCA) embolization caused by clotting or embolus. The embolization of MCA leads to significant encephaledema, as well as the increasing of intracranial pressure, which might induce deterioration of consciousness and fatal outcomes. The mortality rate could be up to $80 \%$, if medical intervention was not acquired immediately. Fatal herniation and life-threatening situation could be occurred due to the mass effect of the swelling tissues [4]. The mortality rate hovers as high as $30 \%$, even if all kinds of decompressing therapies, such as hyperventilation, mannitol, hypertonic saline, and decompressive craniectomy, were performed [5]. As one of mature therapeutic strategy to mMCAI [6], DC has been inscrolled into guidelines as a common practice [7]. Although DC survives patients during the acute stage of mMCAI, the survival quality remains suboptimal and has become the focus of disputes [8]. This systematic 
review attempts to figure out the role of DC in the management of mMCAI, based on previous studies.

\section{Methods}

\section{Literature-search strategy}

Studies were entirely searched since the foundation dates of multiple databases to the same cut-off date of June 2016. All major databases were involved, including Cochrane Central Register of Controlled Trials, EMBASE, MEDLINE, and other sources. The key words were 'decompressive craniectomy', 'decompressive hemicraniectomy', 'middle cerebral artery infarction', 'middle cerebral artery infarction occlusion'. with MeSH extended to broaden the search. Retrieved studies, review articles, and conference abstracts were excluded.

\section{Inclusion and exclusion criteria}

Inclusion criteria: 1) 2-arm studies consist of both DC group and control group (control group was defined as the participants underwent conventional management); 2) $\geq 18$ years old with a defined diagnose of mMCAI according to clinical or radiological evidences; 3 ) $\geq 1$ outcome of interests was involved in the literature. The primary outcome was defined as the alteration of mRS score. The secondary outcomes include the scores of National Institute of Health Stroke Scale (NIHSS) and Barthel Index Score(BIS).

Excluded criteria: editorials, letters to the editor, review articles, case reports, and animal experimental studies were excluded.

\section{Quality assessment and statistical analysis}

According to the criteria of Centre for Evidence-Based Medicine in Oxford, UK [9], all the studies involved were rated into different level. RCTs were assessed referring to Cochrane risk of bias tool in six aspects [10], including generation of random sequence, allocation concealment, blinding, incomplete outcome data, selective reporting, and other bias.

Newcastle-Ottawa Scale(NOS) [11, 12] was applied in the qualitative evaluation of retrospective and prospective cohort studies. The rule of star-grading was defined as following: selection of subjects(4 stars), comparability of groups ( 2 stars) and measurement of exposure (3 stars). The total score of NOS was nine stars. High-grade was identified as stars ranked $\geq 6$.

After risk bias assessment, meta-analysis was performed through Review Manager 5.3 (Cochrane Collaboration, Oxford, UK). Odds Ratio and 95\% confidence intervals was taken into account as the measurements of Dichotomous. $\mathrm{T}^{2}$ (tau-squared) test, $\mathrm{I}^{2}$ test, and chi-square tests were used for statistical heterogeneity evaluation for each meta-analysis result. An $\mathrm{I}^{2}<25 \%$

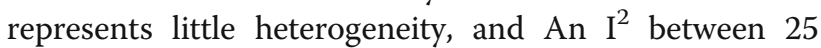

Table 1 Modified Rankin Scale

Score performance

1. No disability

2. No significant disability; able to carry out all activities despite symptoms

3. Slight disability: no assistance but unable to carry out previous activities

4. Moderate disability: requiring some help, but able to work

5. Moderate severe disability: requiring assistance to walk and to attend to own bodily needs

6. Severe disability: bedridden, incontinent, and requiring constant nursing care 7. Death

and $50 \%$ represents moderate heterogeneity, in which fixed-effect model would be conducted secondly. Meanwhile, significant heterogeneity was defined as an $\mathrm{I}^{2}>$ $50 \%$, and random effects models would be conducted. Mantel-haenszel method was used in the process of summary estimations. The results got statistical significance

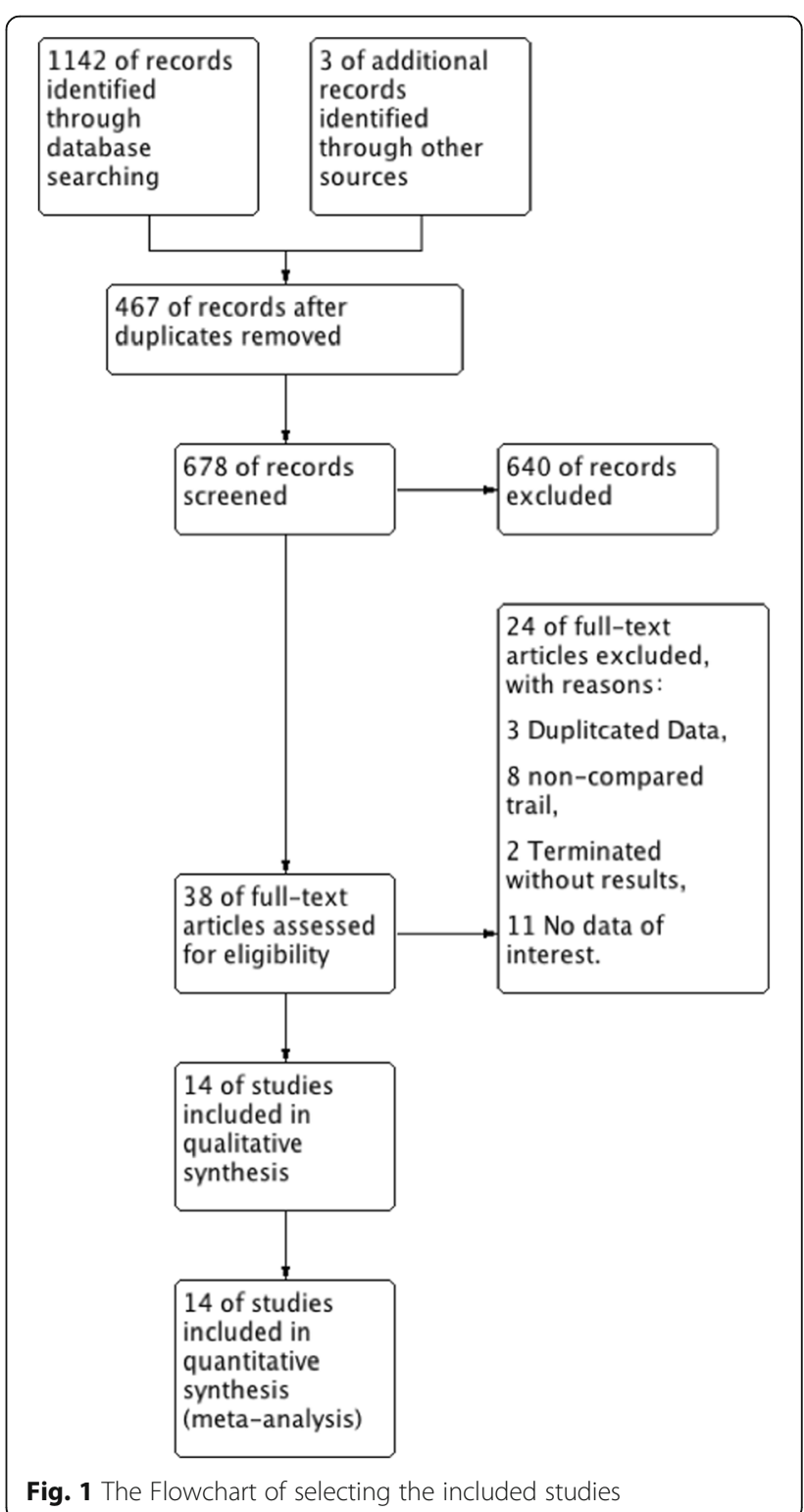


when $P<0.05$. Publication bias was mapped referring to Runnel plots.

\section{Outcome measurements}

Modified Rankin Scale (mRS) had been widely used, as a daily activity-based scale, in the measurement of neurological deficit patients induced by stroke or other neurological diseases (Table 1). The scale was completed by the clinical physicians. It runs from 0 , which refers to perfect health without symptoms, to 6, which means death. According to the scale, suboptimal outcome was defined as $\mathrm{mRS}>3$, which suggested that patient was suffering from at least three moderate disabilities. Because of the declaration of mismatching between mRS score and clinically symptom, equivalent scales were added in secondary outcomes as supplements [13].

\section{Results}

Search results: an assessment of risk of bias

According to the Literature-search strategy, 1145 records of data were critically identified and collected through databases (Fig. 1). Fourteen of them were finally included to the meta-analysis, including eight RCT [14-21] and six retrospective cohort studies [22-27]. The 423 DC cases and 389 conservative managed cases were involved. The features of included studies were shown in Table 2 . Although some of the trials declared themselves randomized studies, the random performance bias and allocation concealment were not that clear (Fig. 2a, b). The trial

Table 2 Characteristics of included studies

\begin{tabular}{|c|c|c|c|c|c|c|c|}
\hline & Study design & $\begin{array}{l}\text { No. of patients } \\
\text { (DC/total) }\end{array}$ & $\begin{array}{l}\text { Age } \\
(\text { Mean } \pm S D)\end{array}$ & $\begin{array}{l}\text { Sex } \\
\text { (Male/Female) }\end{array}$ & Time to treatment & $\begin{array}{l}\text { Duration of } \\
\text { follow-up }\end{array}$ & NIHSS \\
\hline \multirow[t]{2}{*}{ DECIMAL 2007 [13] } & $\mathrm{RCT}$ & $20 / 38$ & $43.5 \pm 9.7$ & $9 / 11$ & $12-36 \mathrm{~h}$ & 6,12 & $22.5(16-35)$ \\
\hline & & & $43.3 \pm 7.1$ & $9 / 9$ & & & $23.4(17-38)$ \\
\hline \multirow[t]{2}{*}{ DESTINY 2007 [14] } & $\mathrm{RCT}$ & $17 / 32$ & $43.2 \pm 9.7$ & $8 / 9$ & $12-36 h$ & 6,12 & $21(19-26)$ \\
\hline & & & $46.1 \pm 8.4$ & $7 / 8$ & & & $24(19-31)$ \\
\hline \multirow[t]{2}{*}{ DESTINY II 2014 [15] } & $\mathrm{RCT}$ & $49 / 112$ & $70(62-82)$ & $25 / 24$ & $<48 h$ & 6,12 & $20(15-40)$ \\
\hline & & & $70(61-80)$ & $31 / 32$ & & & $21(15-38)$ \\
\hline \multirow[t]{2}{*}{ HAMLET [16] } & $\mathrm{RCT}$ & $32 / 64$ & $50.0 \pm 8.3$ & $20 / 12$ & $<96 h$ & $3,6,12$ & $23(17-34)$ \\
\hline & & & $47.4 \pm 9.8$ & $18 / 14$ & & & $24(20-36)$ \\
\hline \multirow[t]{2}{*}{ HAMLET ॥ [17] } & $\mathrm{RCT}$ & $32 / 64$ & $50.0 \pm 8.3$ & $20 / 12$ & $<96 \mathrm{~h}$ & $3,6,12,36$ & $23(17-34)$ \\
\hline & & & $47.4 \pm 9.8$ & $18 / 14$ & & & $24(20-36)$ \\
\hline \multirow[t]{2}{*}{ HeADDFIRST [18] } & $\mathrm{RCT}$ & $14 / 24$ & $52.3(45-59)$ & $9 / 5$ & $<96 \mathrm{~h}$ & 6 & $\mathrm{~N} / \mathrm{A}$ \\
\hline & & & $57.9(45-66)$ & $6 / 4$ & & & \\
\hline \multirow[t]{2}{*}{ Slezins 2012 [19] } & $\mathrm{RCT}$ & $11 / 24$ & $57.2(49-81)$ & N/A & $<48 \mathrm{~h}$ & 12 & $21.2(16-28)$ \\
\hline & & & $65.0(49-81)$ & & & & $20.8(17-24)$ \\
\hline \multirow[t]{2}{*}{ Zhao 2012 [20] } & $\mathrm{RCT}$ & $24 / 47$ & $63.5(29-78)$ & $6 / 18$ & $<48 \mathrm{~h}$ & 6,12 & N/A \\
\hline & & & $64.0(32-80)$ & $7 / 16$ & & & \\
\hline Mohammed 2014 [21] & $\mathrm{R}$ & $90 / 125$ & $53.8 \pm 7.1(34-35)$ & $\mathrm{N} / \mathrm{A}$ & $<24 h$ & 3,6 & N/A \\
\hline \multirow[t]{2}{*}{ Rai 2014 [22] } & $P$ & $36 / 60$ & $44.3 \pm 12.23$ & $27 / 16$ & $<148 h$ & $3,6,12$ & $19.0 \pm 3.3$ \\
\hline & & & $57.12 \pm 19.28$ & & & & $18.4 \pm 3.8$ \\
\hline \multirow[t]{2}{*}{ Tsai 2012 [23] } & $P$ & $37 / 79$ & $65.5 \pm 15.8$ & $18 / 19$ & $<48 \mathrm{~h}$ & 6 & N/A \\
\hline & & & $75.9 \pm 13.8$ & $22 / 20$ & & & \\
\hline \multirow[t]{2}{*}{ Yang 2015 [24] } & $\mathrm{R}$ & $10 / 24$ & $58.7 \pm 19.3$ & $5 / 5$ & $120 \mathrm{~h}$ & 3 & $16.1 \pm 1.9$ \\
\hline & & & $65.9 \pm 16.5$ & $10 / 4$ & & & $16.5 \pm 2.4$ \\
\hline \multirow[t]{2}{*}{ Yu 2012 [25] } & $\mathrm{R}$ & $58 / 131$ & $62.1 \pm 12.4$ & $35 / 23$ & $<48 \mathrm{~h}$ & 6 & 16.2 \\
\hline & & & $72.6 \pm 9.4$ & $36 / 37$ & & & 16.8 \\
\hline \multirow[t]{2}{*}{ Rahamnian 2014 [26] } & $P$ & $30 / 60$ & $59.0 \pm 13.5$ & $22 / 29$ & $<48 \mathrm{~h}$ & 3 & $\mathrm{~N} / \mathrm{A}$ \\
\hline & & & $62.1 \pm 11.0$ & 16.14 & & & \\
\hline
\end{tabular}

$R$ Retrospective, $P$ Prospective, DECIMAL decompressive craniectomy in malignant middle cerebral artery infarction, DESTINY Decompressive Surgery for the Treatment of Malignant Infarction of the Middle Cerebral Artery, HAMLET Hemicraniectomy in older patients with extensive middle-cerebral-artery stroke, HeADDFIRST Hemicraniectomy and durotomy upon deterioration from infarction-related swelling trial 
would be considered incomplete if some important data were inadequate, such as the follow-up information in 6th month or later. Unfortunately, most of the retrospective studies demonstrated a low quality due to failing to complete the double-blind in researches and inappropriate random sequence generation (Fig. 2c).

\section{Incidence of unfavorable outcome}

Fourteen studies included (8 RCTs and six retrospective studies) were analyzed to evaluate the incidence of suboptimal outcomes of MCAIs. The longest follow-up span was 36 weeks. No statistical heterogeneity was found among these studies ( $\mathrm{I} 2=15 \%, P>0.1$ ). A fixed effect model (Mantel-Haenszel method) was applied as well. The combined odds ratios and 95\% CI were 0.23
$(0.15,0.35), P<0.01$, indicating that DC was relevant to the reducing incidence of suboptimal outcomes (Fig. 3). No significantly asymmetry was found in the shape of funnel plot in our study. Furthermore, the studies were divided into several subgroups according to their different follow-up time. Pooled effect value was calculated between five studies with a follow-up of 3 months and the same analysis was performed on nine studies with a follow-up of 6 months and seven studies with 12 months' follow-up. No statistical heterogeneity was found between three subgroups, and the pooled OR values $(95 \% \mathrm{CI})$ of DC and unfavorable outcome were $0.07(0.02,0.21), 0.20(0.12$, 0.33) (Fig. 4). Another subgroup analysis which grouped by ages (age $\leq 60$ years and age $>60$ years) was carried (Fig. 5), unfavourable outcome was applied to outcome
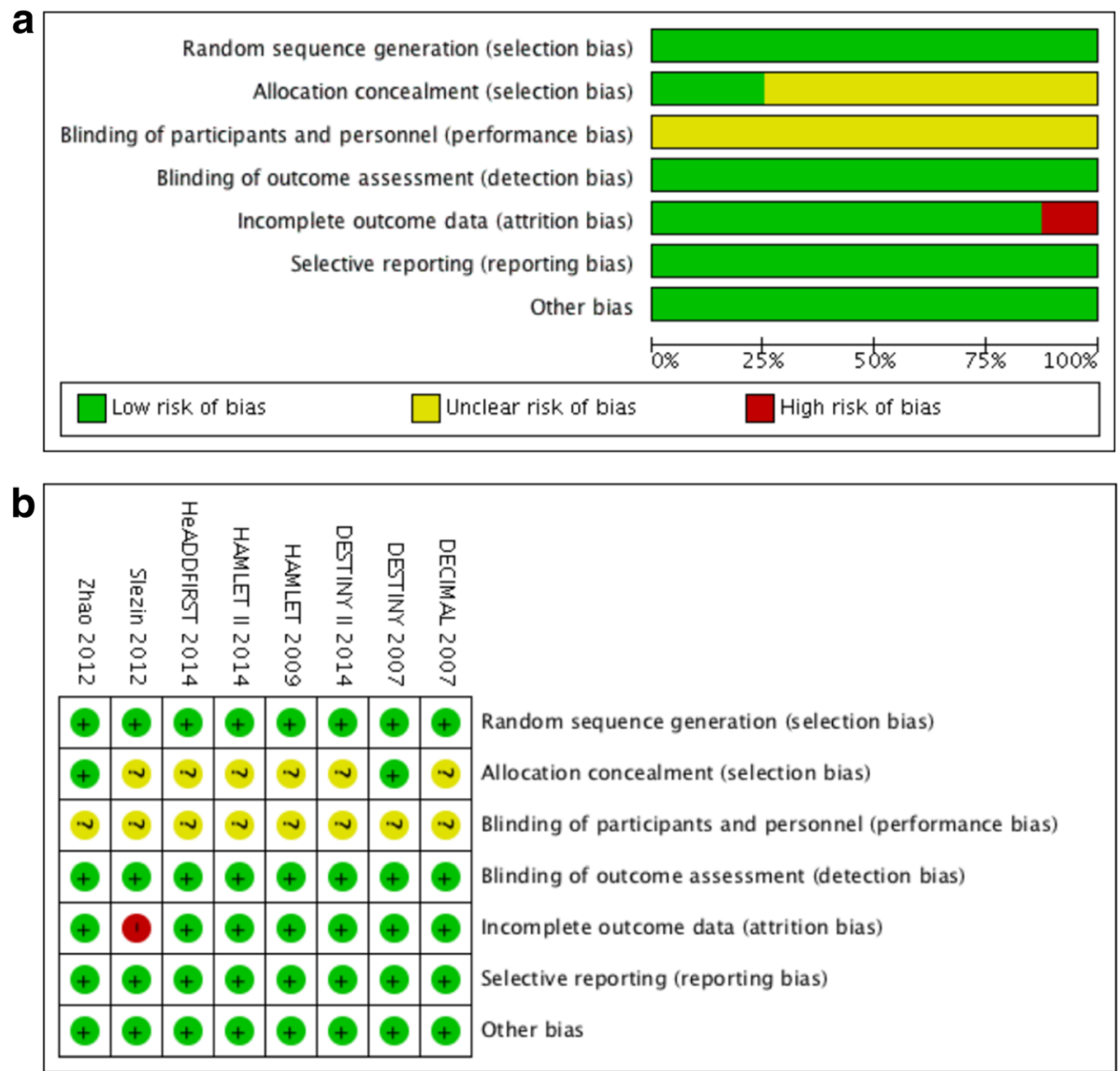

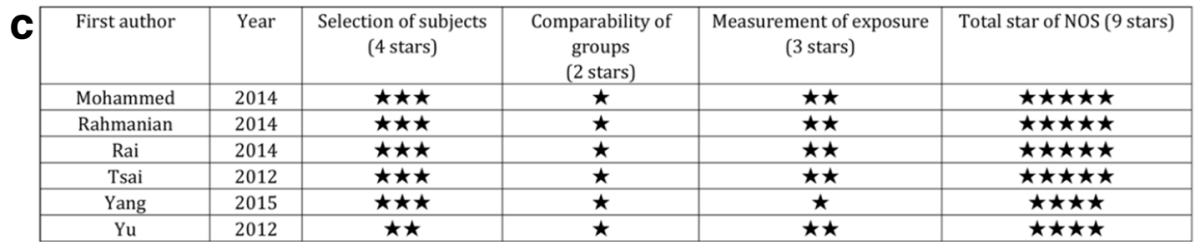

Fig. 2 a Risk of bias summary showing our judgments about each risk of bias item for each included study. Green plus sign =low risk; red minus sign = high risk; yellow question mark = not reported; blank = unclear risk. $\mathbf{b}$ Risk of bias graph showing our judgments about each risk of bias item for each included study. c Quality assessment of four observational studies with NOS 


\begin{tabular}{|c|c|c|c|c|c|c|c|c|c|}
\hline & \multirow{2}{*}{ Study or Subgroup } & $\begin{array}{l}\text { DC } \\
\text { Events } \\
\end{array}$ & Total & \multicolumn{2}{|c|}{$\begin{array}{l}\text { Medical } \\
\text { Events Total }\end{array}$} & Weight & \multirow[t]{2}{*}{$\begin{array}{c}\text { Odds Ratio } \\
\text { M- } \mathrm{H} \text {, Fixed, } 95 \% \mathrm{Cl}\end{array}$} & \multicolumn{2}{|c|}{$\begin{array}{c}\text { Odds Ratio } \\
\text { M-H, Fixed, } 95 \% \mathrm{Cl}\end{array}$} \\
\hline & & 15 & 20 & 17 & 18 & $4.4 \%$ & & & \\
\hline & DESTINY 2007 & 9 & 17 & 11 & 15 & $5.4 \%$ & $\quad 0.41[0.09,1.81]$ & $\longrightarrow$ & \\
\hline & DETINY II 2014 & 44 & 47 & 59 & 62 & $3.2 \%$ & $0.75[0.14,3.87]$ & 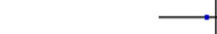 & \\
\hline & HAMLET 2009 & 16 & 21 & 14 & 18 & $3.5 \%$ & $0.91[0.20,4.09]$ & & \\
\hline & HAMLET II 2014 & 16 & 21 & 14 & 18 & $3.5 \%$ & $0.91[0.20,4.09]$ & 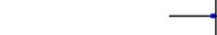 & - \\
\hline & HeADDFIRT 2014 & 5 & 6 & 4 & 4 & $1.1 \%$ & $0.41[0.01,12.64]$ & & \\
\hline & Mohammed 2014 & 32 & 90 & 29 & 35 & $26.3 \%$ & $0.11[0.04,0.30]$ & $\rightarrow-$ & \\
\hline & Rahmanian 2014 & 21 & 30 & 29 & 30 & $8.5 \%$ & $0.08[0.01,0.68]$ & & \\
\hline & Rai 2014 & 29 & 36 & 24 & 24 & $5.8 \%$ & $0.08[0.00,1.48]$ & 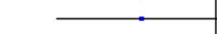 & \\
\hline & Slezins 2012 & 6 & 11 & 13 & 13 & $5.6 \%$ & $0.04[0.00,0.92]$ & 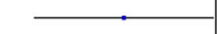 & \\
\hline & Tsai 2012 & 32 & 37 & 42 & 42 & $5.6 \%$ & $0.07[0.00,1.30]$ & & \\
\hline & Yang 2015 & 3 & 5 & 14 & 14 & $3.4 \%$ & $0.05[0.00,1.25]$ & & \\
\hline & Үu 2012 & 39 & 58 & 65 & 73 & $18.4 \%$ & $0.25[0.10,0.63]$ & $\rightarrow-$ & \\
\hline & Zhao 2012 & 18 & 24 & 21 & 23 & $5.2 \%$ & $0.29[0.05,1.60]$ & & \\
\hline & Total $(95 \% \mathrm{Cl})$ & & 423 & & 389 & $100.0 \%$ & $0.23[0.15,0.35]$ & $\bullet$ & \\
\hline & Total events & 285 & & 356 & & & & & \\
\hline & $\begin{array}{l}\text { Heterogeneity. } \mathrm{Ch}^{2}= \\
\text { Test for overall effect: }\end{array}$ & $\begin{array}{l}15.32, d f \\
Z=6.88\end{array}$ & $\begin{array}{l}=13 \\
(P<0 .\end{array}$ & $\begin{array}{l}\langle P=0.291 \\
.000011\end{array}$ & & & & 0.001 & $\frac{10}{10} 1000$ \\
\hline
\end{tabular}

across all groups. The funnel plot shows approximately symmetrically ranged around the overall effect size estimate, shown by the dashed line in the center (Fig. 6).

\section{Discussion}

This meta-analysis suggests that DC has a positive effect on the decreasing of suboptimal outcomes of mMCAI, even though the morbidity rate still remains unclear. This study has included all the latest study of MCAI and made some progress in the analytic process. The studies involved were not exactly the same as previous metaanalysis works. Some of the studies, quoted by previous meta works as RCTs, were downgrade precisely to quasi-RCTs [28] in our study, for their potential bias

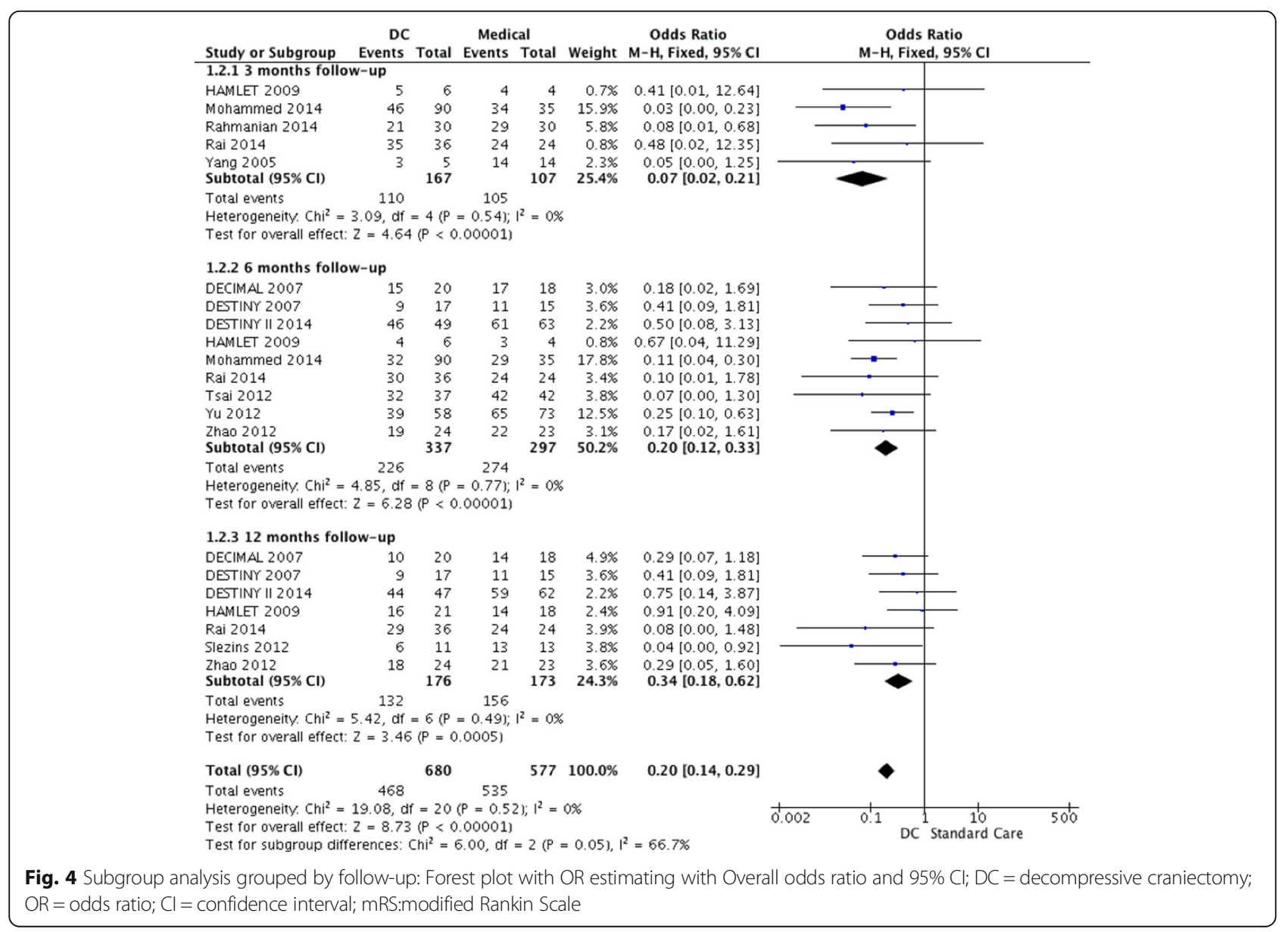




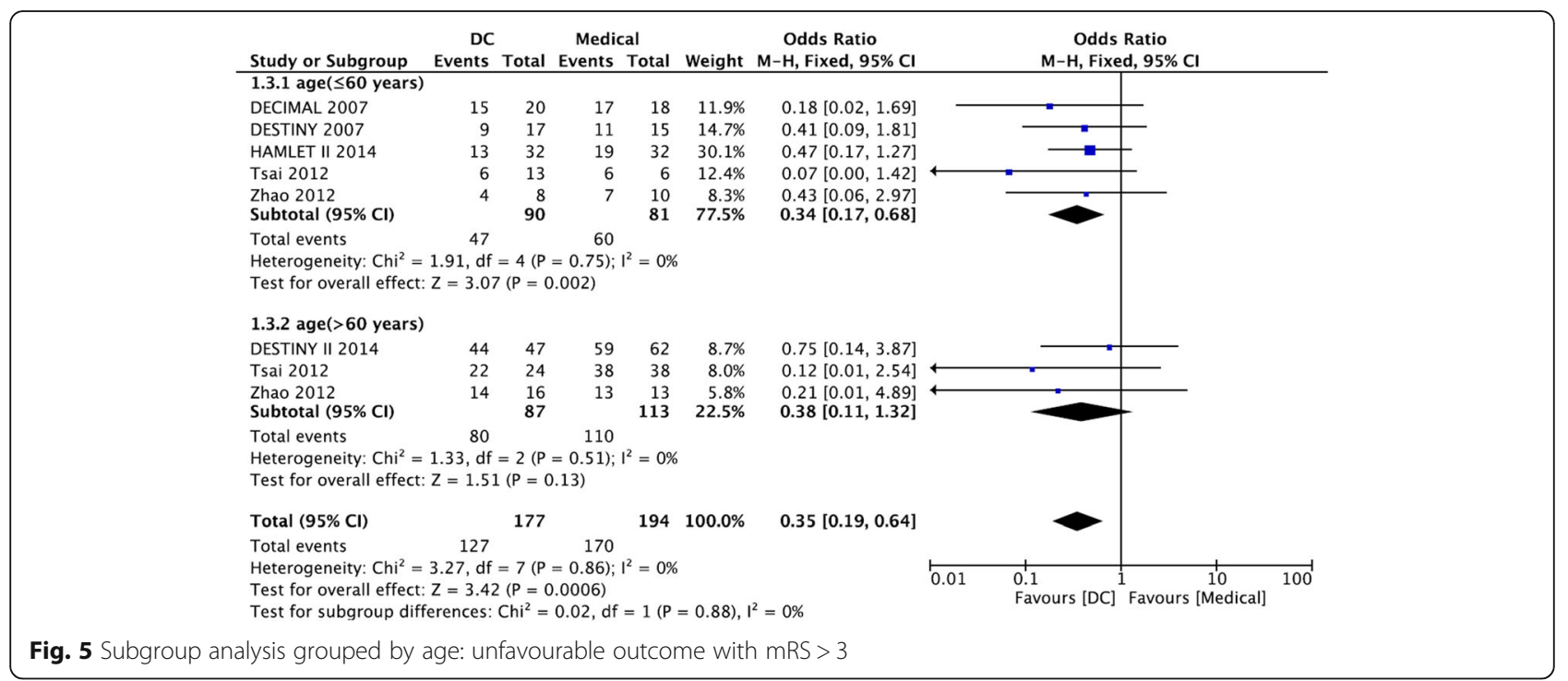

that might have influence on results. The QuasiRCT is defined as allocating the studies throughout some general characteristics of cases, such as date of birth, day of the week, medical record number, and month of the year, among others. The mismatching between mRS score and clinically manifestation is common in clinical practical [13]. Although Bathel Index score and NIHSS $[15,16]$ can make disability or dependence of stroke patients in daily activities quantifiable, Modified Rankin Scale is an more acceptable and pragmatic Scale to quantify their outcome. In this study, the suboptimal outcome was defined as a mRS score $>3$. The reducing of mRS score indicates an improvement of patients' neurological function when DC is performed.

Some retrospective cohort studies were involved in our study to increase the sample size, for the participants of
RCTs were not sufficient relatively. Some high quality retrospective studies were involved critically [29]. The retrospective studies are coincidence with the real-world researches [30].

However, some issues of DC remain controversial. Current research appears to validate such a view that differentiating outcome between adult patients ( $<60$ years) and elderly patients ( $>60$ years). Most studies developed the claim that age was a independent factor affecting the prognosis. Some studies' finding lend support for that the benefit of DC on functional outcome may exist in adult patients, not in elder patients. The age of patients can be prognostic factors independently, while tragedy always happened in ageing. Some well-designed study which focused elder patients only, DESTINY II, for example, favors medical care more than other studies which focused both

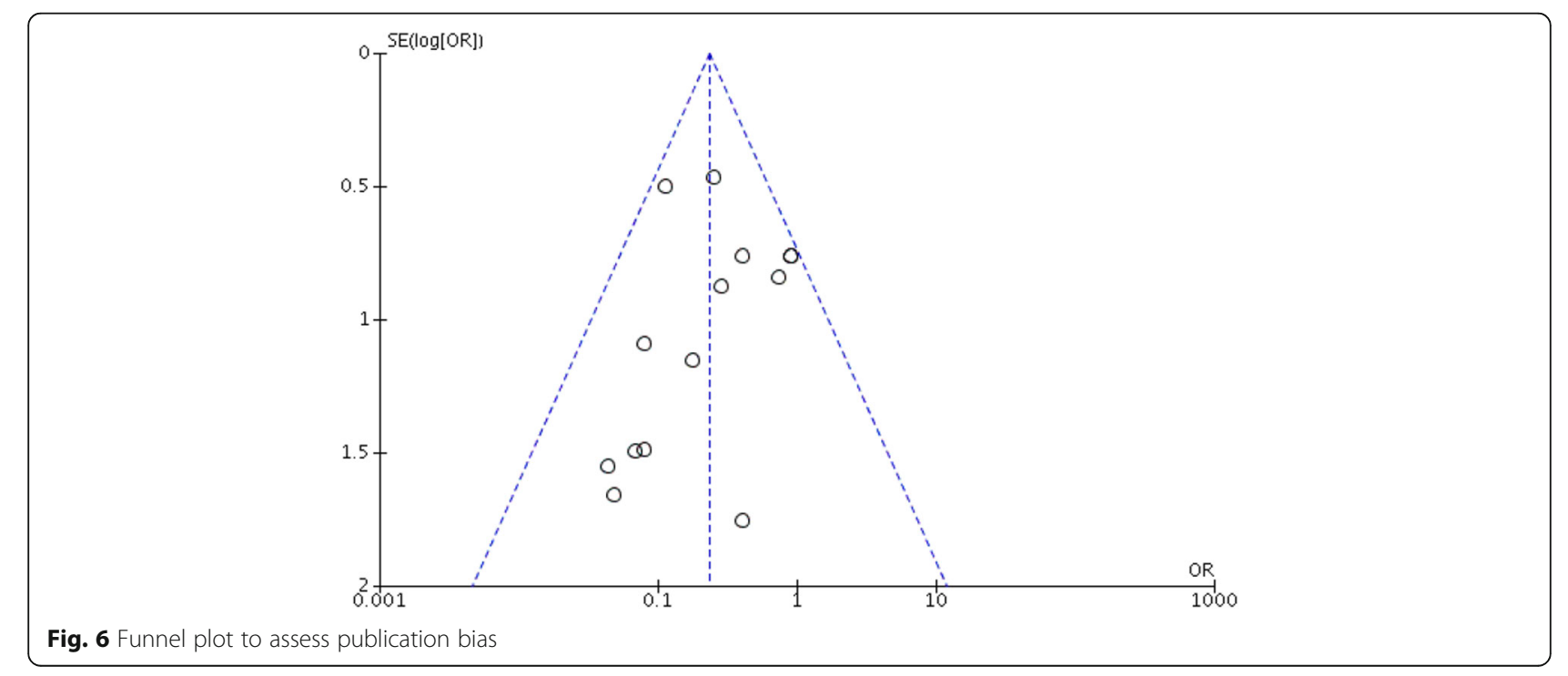


adults and the old. However, Grouped by ages, subgroup analysis show slight difference between adult patients and elderly patients in unfavorable outcome (Odds Ratio = $0.34,95 \% \mathrm{CI}[0.17,0.68] ; \mathrm{OR}=0.38,95 \% \mathrm{CI}[0.11,1.32]$, respectively). The effectiveness of $\mathrm{DC}$ in the elderly subpopulation remain questionable. It is difficult to achieve a consensus about the indication of DC and intraoperative technology nodes. The operative indication draws most of focus among those disputations. In clinical practice, DC is the "trump card" when all other managements fails or fatal situation presents, such as intractable intracranial hypertension. For its important role, the operative indication should be evaluated strictly and prudently.

For traumatic brain injury, positive early decompression management could reduce the incidence of secondary injury [31]. And the age always act as an independent risk factor of prognosis, suboptimal outcome appears in those elder participants. Recent registry studies have proved more strong prognostic predictors, including type of infarction occlusion and blood sugar level.

The conclusion drawn from this study is limited for the heterogeneity of different studies involved in. Further researches are urgently needed in both clinical trials, such as RCTs and real-world researches, and fundamental researches, including molecular mechanism studies, pathological researches, and animal experimentations. Not only for the developing progress of mMCAI, but also for the protecting mechanism of $\mathrm{DC}$, in purpose of provide evidence-based operative indication, timing selection principle and perioperative management strategy.

\section{Conclusions}

In conclusion, according to the available evidence, our study demonstrated DC can ameliorate the suboptimal outcome of mMCAI patients.

\section{Abbreviations \\ Cl: Confidence interval; DC: Decompressive craniectomy; DECIMAL: Decompressive craniectomy in malignant middle cerebral artery infarction; DESTINY: Decompressive surgery for the treatment of malignant infarction of the middle cerebral artery; HAMLET: Hemicraniectomy in older patients with extensive middle-cerebral-artery stroke; HeADDFIRST: Hemicraniectomy and durotomy upon deterioration from infarction-related swelling trial; mMCAl: Malignant middle cerebral artery infarctions; mRS: Modified Rankin Scale; NIHSS: National Institute of Health stroke scale; OR: Odds ratio; P: Prospective; R: Retrospective; RCTs: Randomized controlled trials}

\section{Acknowledgements}

The following individuals helped with data collection: Neurosurgeons Dezhi Li, Jiayi Qiu, Jinqian Dong, Yang Zhang and Peng Kang.

\section{Funding}

There is no funding supported for this research.

\section{Availability of data and materials}

The datasets used and analyzed during the current study available from the corresponding author on reasonable request.

\section{Authors' contributions}

LX: designing the study, collecting references, making the meta-analyzing data and writing the manuscript; $T L$ : collecting references and helping the mata-analysis procedures; XT: collecting references and revising the English writing; DW: revise the manuscript; WL: modifying the meta-analysis, providing critical revisions and designing the study; $J$ : discussion and approving the final version of the manuscript; BL: approving the final version of the manuscript. All authors read and approved the final manuscript.

\section{Competing interests}

The authors declare that they have no competing interests.

\section{Consent for publication}

All the data in this research are from public papers. We don't need patients' consent for publication.

\section{Ethics approval and consent to participate}

We declare that the researchers have no conflict of interests. This mata-analysis article is a systematic evaluation based on references collecting. It does not contain any studies with human participants and animals performed by any of the authors.

\section{Author details}

${ }^{1}$ Department of Neurosurgery, Beijing Tiantan Hospital, Capital Medical University, 6 Tiantan Xili, Dongcheng District, Beijing 100050, People's Republic of China. ${ }^{2}$ China National Clinical Research Center for Neurological Diseases (NCRC-ND), Beijing 100050, China. ${ }^{3}$ Department of Neurology, Beijing

Tiantan Hospital, Capital Medical University, 6 Tiantan Xili, Beijing 100050, China.

Received: 9 February 2017 Accepted: 10 May 2017

Published online: 04 July 2017

\section{References}

1. Guerra WK, Gaab MR, Dietz H, et al. Surgical decompression for traumatic brain swelling: indications and results. J Neurosurg. 1999;90(2):187-96.

2. Cushing $\mathrm{H}$. The establishment of cerebral hernia as a decompressive measure for inaccessible brain tumors; with the description of intramuscular methods of making the bone defect in temporal and occipital regions. Surg Gynecol Obstet. 1905; 1:297-314.

3. Chu SY, Sheth KN. Decompressive craniectomy in neurocritical care. Curr Treat Options Neurol. 2015;17(2):1-11.

4. Hacke W, Schwab S, Horn M, et al. 'Malignant' middle cerebral artery territory infarction: clinical course and prognostic signs. J Archives of Neurology. 1996; 53(4):309-15.

5. Pillai A, Menon SK, Kumar S, et al. Decompressive hemicraniectomy in malignant middle cerebral artery infarction: an analysis of long-term outcome and factors in patient selection. J Neurosurg. 2007;106(1):59-65.

6. Neugebauer $\mathrm{H}$, Jüttler E. Hemicraniectomy for malignant middle cerebral artery infarction: Current status and future directions. Int J Stroke. 2014;9(4): 460-7.

7. Socialstyrelsen. Hjärninfarkt med expansiv effekt (malign mediainfarkt) hos patienter under cirka 60 år. Nationella riktlinjer för strokesjukvård 2009—Stöd för styrning och ledning. Stockholm: The National Board of Health and Welfare; 2009.

8. Rahme R, Zuccarello M, Kleindorfer D, et al. Decompressive hemicraniectomy for malignant middle cerebral artery territory infarction: is life worth living? J Neurosurg. 2012;117(4):749-54.

9. Phillips B, Ball C, Badenoch D, et al. Oxford centre for evidence-based medicine levels of evidence (May 2001). BJU international. 2011;107(5):870.

10. Higgins J, Green S. Cochrane handbook for systematic reviews of interventions. New York: Cochrane Collaboration, John Wiley and Sons; 2008.

11. Taggart DP, D'Amico R, Altman DG. Effect of arterial revascularisation on survival: a systematic review of studies comparing bilateral and single internal mammary arteries. Lancet. 2001;358:870-5.

12. Wells GA, Shea B, O'Connell D, Peterson J, Welch V, Losos M, et al. The Newcastle-Ottawa Scale (NOS) for assessing the quality if nonrandomized studies in meta-analyses. Available from: http://www.ohri.ca/programs/ clinicaLepidemiology/oxford.htm.

13. Debiais S, Gaudron-Assor M, Sevin-Allouet M, et al. Ethical considerations for craniectomy in malignant middle cerebral artery infarction: should we still deny our patient a life-saving procedure? Int J Stroke. 2015;10(7):2-4. 
14. Vahedi K, Vicaut E, Mateo J, et al. Sequential-design, multicenter, randomized, controlled trial of early decompressive craniectomy in malignant middle cerebral artery infarction (DECIMAL Trial). J Stroke. 2007;38(9):2506-17.

15. Jüttler E, Schwab S, Schmiedek P, et al. Decompressive surgery for the treatment of malignant infarction of the Middle Cerebral Artery (DESTINY): a randomized, controlled trial. J Stroke. 2007;38(9):2518-25.

16. Jüttler $E$, Unterberg $A$, Woitzik J, et al. Hemicraniectomy in older patients with extensive middle-cerebral-artery stroke. N Engl J Med. 2014;370(12): 1091-100.

17. Hofmeijer J, Kappelle $\sqcup$, Algra A, et al. Surgical decompression for spaceoccupying cerebral infarction (the Hemicraniectomy After Middle Cerebral Artery infarction with Life-threatening Edema Trial [HAMLET]): a multicentre, open, randomised trial. J Lancet Neurology. 2009;8(4):326-33.

18. Geurts M, Hb VDW, Kappelle $\sqcup$, et al. Surgical decompression for space-occupying cerebral infarction: outcomes at 3 years in the randomized HAMLET trial. J Stroke. 2013:44(9):2506-8

19. Frank JI, Schumm LP, Wroblewski K, et al. Hemicraniectomy and durotomy upon deterioration from infarction-related swelling trial: randomized pilot clinical trial. Stroke. 2014;45(3):781-7.

20. Slezins J, Keris V, Bricis R, et al. Preliminary results of randomized controlled study on decompressive craniectomy in treatment of malignant middle cerebral artery stroke. Medicina. 2012;48(10):521-4.

21. Zhao J, Su YY, Zhang Y, et al. Decompressive hemicraniectomy in malignant middle cerebral artery infarct: a randomized controlled trial enrolling patients up to 80 years old. Neurocrit Care. 2012;17(2):161-71.

22. Raffiq MA, Haspani MS, Kandasamy R, et al. Decompressive craniectomy for malignant middle cerebral artery infarction: Impact on mortality and functional outcome. Surg Neurol Int. 2014;5(1):102

23. Rai VK, Bhatia R, Prasad K, et al. Long-term outcome of decompressive hemicraniectomy in patients with malignant middle cerebral artery infarction: a prospective observational study. Neurol India. 2014;62(1):26-31.

24. Tsai CL, Chu H, Peng GS, et al. Preoperative APACHE II and GCS scores as predictors of outcomes in patients with malignant MCA infarction after decompressive hemicraniectomy. Neurol India. 2012;60(6):608-12.

25. Yang XF, et al. Is decompressive craniectomy for malignant middle cerebral artery infarction of any worth? J Zhejiang Univ Sci B. 2005;6:644-9.

26. Yu JW, Choi JH, Kim DH, et al. Outcome following decompressive craniectomy for malignant middle cerebral artery infarction in patients older than 70 years old. J Cerebrovasc Endovasc Neurosurg. 2012;14(2):65-74.

27. Rahmanian A, Seifzadeh B, Razmkon A, et al. Outcome of decompressive craniectomy in comparison to nonsurgical treatment in patients with malignant MCA infarction. Springerplus. 2014;3(1):1-6.

28. Liu W, Bakker NA, Groen RJ. Chronic subdural hematoma: a systematic review and meta-analysis of surgical procedures. J Neurosurg. 2014;121(3):665-73.

29. Riley RD, Lambert PC, Abo-Zaid G. Meta-analysis of individual participant data: rationale, conduct, and reporting. BMJ. 2010;340:c221.

30. Barnes N, Menzies-Gow A, Mansur AH, et al. Effectiveness of omalizumab in severe allergic asthma: a retrospective UK real-world study. J Asthma. 2013; 50(5):529-36.

31. Baethmann A, Maier-hauff K, Kempski O, et al. Mediators of brain edema and secondary brain damage. Crit Care Med. 1988;16(10):972-8.

\section{Submit your next manuscript to BioMed Central and we will help you at every step:}

- We accept pre-submission inquiries

- Our selector tool helps you to find the most relevant journal

- We provide round the clock customer support

- Convenient online submission

- Thorough peer review

- Inclusion in PubMed and all major indexing services

- Maximum visibility for your research

Submit your manuscript at www.biomedcentral.com/submit

) Biomed Central 